\title{
Advance short-term prediction of the large Tokachi-oki earthquake, September 25, 2003, $M=8.1$ A case history
}

\author{
P. Shebalin ${ }^{1}$, V. Keilis-Borok ${ }^{1,2,3}$, I. Zaliapin ${ }^{1,2}$, S. Uyeda ${ }^{4}$, T. Nagao ${ }^{4}$, and N. Tsybin ${ }^{5}$ \\ ${ }^{1}$ International Institute for Earthquake Prediction Theory and Mathematical Geophysics, Russian Ac. Sci., \\ Warshavskoe sh., 79, korp. 2, Moscow, 113556, Russia \\ ${ }^{2}$ Institute of Geophysics and Planetary Physics, University of California, Los Angeles, California, 90095-1567, U.S.A. \\ ${ }^{3}$ Department of Earth and Space Sciences, University of California, Los Angeles, California, 90095-1567, U.S.A. \\ ${ }^{4}$ Earthquake Prediction Research Center, Tokai University, 3-20-1 Orido, Shimizu City, Shizuoka 424, Japan \\ ${ }^{5}$ Russian Federation State Research Center, State Research Institute of Aviation Systems, 7, Victorenko st., Moscow, 125319 Russia
}

(Received November 27, 2003; Revised May 10, 2004; Accepted May 26, 2004)

\begin{abstract}
Tokachi-oki earthquake in northern Japan, September 25, 2003, magnitude 8.1, was predicted six months in advance by a short-term earthquake precursor "chain" that reflects an increase of the correlation range among small earthquakes. This prediction is part of the ongoing test of a new short-term prediction method; the test covers territories of Japan, California, and Eastern Mediterranean. Qualitatively, precursory chain is a dense sequence of small earthquakes that had quickly extended over a long distance. A strong earthquake is expected within nine months after such chain is formed, in its formally defined vicinity. Chains are analyzed in conjunction with intermediate-term precursors, emerging with characteristic lead time of years. Methodology of prediction is named "Reverse Tracing of Precursors" $(R T P)$, since precursors are considered in the reverse order of their appearance. That allows detecting short-term precursors not detectable with direct order of analysis. $R T P$ was tested retrospectively for California, Japan, and Eastern Mediterranean, where 22 more strong earthquakes occurred during the time considered. The concept underlying $R T P$ is interaction of lithosphere dynamics on different temporal scales. The described results enhance our fundamental understanding of lithosphere dynamics and, on the practical side, our capability for earthquakes preparedness.
\end{abstract}

Key words: Advance short-term earthquake prediction, earthquake correlation, Tokachi-oki.

\section{Case History}

A prediction method remains hypothetical until validated by advance predictions. Here we describe the first results of ongoing experiment in advance short term prediction of strong earthquakes by the "Reverse Tracing of Precursors" (RTP) method (Keilis-Borok et al., 2004). This method considers precursors in reverse order of their appearance. First we detect the candidates for short-term precursors emerging months before the earthquake targeted by prediction; in our case the candidates are the chains of small earthquakes capturing the rise of earthquake correlation range. Then we check, for each chain, whether it was preceded within few years by intermediate-term precursors in its close vicinity (Section 2.3). If yes, we regard this chain as a precursory one; in prediction it would start a short-term alarm. If notthe chain is disregarded and alarm is not started. Thus we consider the short-term patterns (chains) first, although they emerge later. This makes possible to detect the precursors undetectable by direct analysis.

Following is a case history of prediction of Tokachi-oki earthquake.

March 27, 2003: Precursory chain emerged.

July 2, 2003: Precursory chain is put on record, as

Copy right(C) The Society of Geomagnetism and Earth, Planetary and Space Sciences (SGEPSS); The Seismological Society of Japan; The Volcanological Society of Japan; The Geodetic Society of Japan; The Japanese Society for Planetary Sciences; TERRAPUB. shown in Fig. 1 and Table 1; they are copied from the poster presented on July 2, 2003 at the Hagiwara Symposium on earthquake prediction during the XXIII Assembly of IUGG. ${ }^{1}$

Sept. 25, 2003: Tokachi-oki earthquake (near Hokkaido island, Japan, magnitude 8.1) occurred as predicted, that is in the vicinity of the chain (Fig. 1), almost six months after the chain emerged (Table 1); this is within the duration of alarm, 9 months, set up by retrospective analysis.

This completes the case history per se. In Section 2 we briefly describe prediction methodology, in Section 3-its applications.

\section{Methodology $y^{2}$}

The problem of earthquake prediction consists of narrowing down the time interval, area, and magnitude interval, where a strong earthquake should be expected. Five major stages of earthquake prediction are usually distinguished. The background stage is estimation of seismic hazard. Other

\footnotetext{
${ }^{1}$ Comparing with the figures in the poster we added for convenience the epicenter of the subsequent Tokachi-oki earthquake.

${ }^{2} R T P$ methodology takes advantage of the concept and ample knowhow developed during previous research in non-linear dynamics and intermediate-term earthquake prediction. To make the present paper selfcontained one may add to it the overview of previous findings (KeilisBorok, 2002) available at http://arjournals.annualreviews.org/doi/full/ 10.1146/annurev.earth.30.100301.083856. More detailed description of these findings is given in (Keilis-Borok and Soloviev (eds.), 2003) and references therein.
} 


\subsubsection{8-2003.03.31}

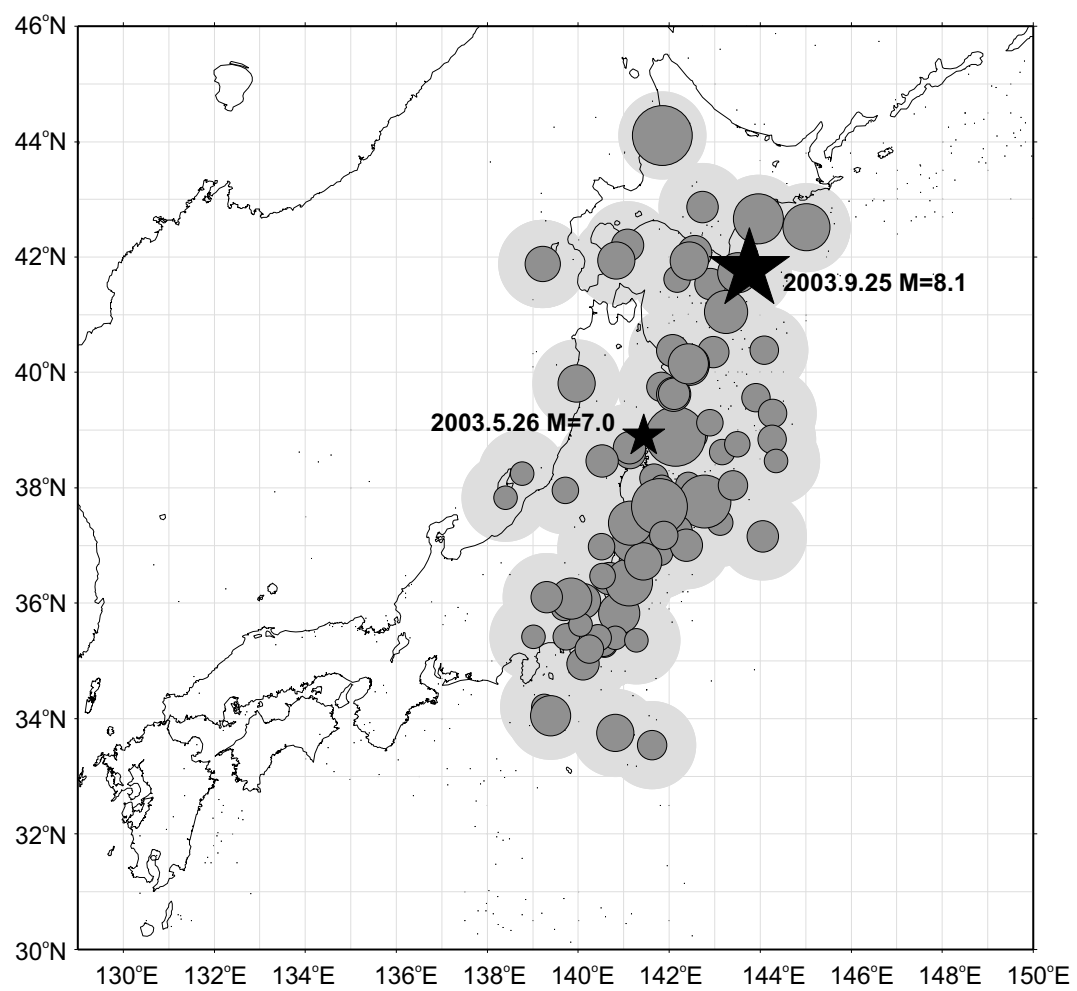

Fig. 1. Japan: precursory chain reported in Shebalin et al. (2003). Circles show epicenters forming the chain; their size is proportional to magnitude. The shadowed area shows $R$-vicinity of the chain. Large star shows the epicenter of Tokachi-oki earthquake, $\mathrm{M}=8.1$, predicted by the chain 6 months in advance.

Table 1. Precursory chain of earthquakes before Tokachi-oki earthquake, $M=8.1$, September 25, 2003.

\begin{tabular}{|c|c|c|c|c|c|c|c|c|c|c|c|}
\hline \# & Date & $\mathrm{m}$ & 24 & 2002.10 .25 & 4.5 & 48 & 2002.12 .20 & 3.7 & 72 & 2003.02 .13 & 3.9 \\
\hline 1 & 2002.09 .08 & 3.8 & 25 & 2002.10 .26 & 4.8 & 49 & 2002.12 .28 & 3.8 & 73 & 2003.02 .14 & 3.8 \\
\hline 2 & 2002.09 .09 & 4.1 & 26 & 2002.10 .31 & 4.1 & 50 & 2003.01 .06 & 3.6 & 74 & 2003.02 .16 & 5.0 \\
\hline 3 & 2002.09 .17 & 3.8 & 27 & 2002.11 .02 & 4.0 & 51 & 2003.01 .14 & 3.7 & 76 & 2003.02 .20 & 3.8 \\
\hline 4 & 2002.09 .25 & 4.0 & 29 & 2002.11 .04 & 3.7 & 52 & 2003.01 .15 & 4.2 & 77 & 2003.02 .21 & 3.6 \\
\hline 5 & 2002.09 .25 & 3.7 & 28 & 2002.11 .03 & 6.1 & 53 & 2003.01 .15 & 3.9 & 75 & 2003.02 .19 & 6.1 \\
\hline 6 & 2002.09 .28 & 4.4 & 30 & 2002.11 .14 & 4.0 & 54 & 2003.01 .24 & 3.8 & 78 & 2003.02 .23 & 4.2 \\
\hline 7 & 2002.09 .30 & 4.2 & 31 & 2002.11 .14 & 4.1 & 55 & 2003.01 .25 & 4.0 & 79 & 2003.02 .24 & 4.6 \\
\hline 8 & 2002.09 .30 & 3.6 & 32 & 2002.11 .16 & 4.2 & 56 & 2003.01 .27 & 4.2 & 80 & 2003.02 .26 & 3.6 \\
\hline 9 & 2002.10 .01 & 3.6 & 33 & 2002.11 .20 & 4.2 & 57 & 2003.01 .27 & 3.9 & 81 & 2003.02 .27 & 3.7 \\
\hline 10 & 2002.10 .02 & 3.6 & 34 & 2002.11 .22 & 3.6 & 58 & 2003.01.27 & 3.7 & 82 & 2003.02 .28 & 4.1 \\
\hline 11 & 2002.10 .03 & 3.7 & 35 & 2002.11 .22 & 3.9 & 59 & 2003.01 .28 & 3.7 & 83 & 2003.03 .02 & 4.0 \\
\hline 12 & 2002.10 .03 & 3.9 & 36 & 2002.11 .22 & 4.0 & 61 & 2003.01 .28 & 3.6 & 84 & 2003.03 .02 & 3.8 \\
\hline 13 & 2002.10 .05 & 3.8 & 37 & 2002.11 .24 & 4.3 & 60 & 2003.01 .28 & 4.9 & 86 & 2003.03 .04 & 4.4 \\
\hline 14 & 2002.10 .07 & 3.9 & 38 & 2002.11 .26 & 3.7 & 62 & 2003.01 .30 & 3.7 & 87 & 2003.03 .09 & 3.6 \\
\hline 16 & 2002.10 .11 & 3.9 & 39 & 2002.11 .30 & 5.2 & 63 & 2003.01 .31 & 3.8 & 85 & 2003.03 .03 & 5.8 \\
\hline 15 & 2002.10 .11 & 5.2 & 40 & 2002.12 .01 & 5.4 & 64 & 2003.01 .31 & 4.4 & 88 & 2003.03 .09 & 4.5 \\
\hline 17 & 2002.10 .11 & 3.7 & 42 & 2002.12 .04 & 3.6 & 65 & 2003.02 .03 & 4.3 & 89 & 2003.03 .09 & 3.9 \\
\hline 19 & 2002.10 .13 & 4.2 & 41 & 2002.12 .04 & 4.7 & 66 & 2003.02 .04 & 3.9 & 90 & 2003.03 .13 & 4.8 \\
\hline 18 & 2002.10 .12 & 5.6 & 43 & 2002.12 .08 & 4.1 & 67 & 2003.02 .08 & 3.9 & 91 & 2003.03 .17 & 4.1 \\
\hline 21 & 2002.10 .17 & 3.6 & 44 & 2002.12 .09 & 4.6 & 68 & 2003.02 .11 & 4.5 & 92 & 2003.03 .18 & 3.6 \\
\hline 20 & 2002.10 .16 & 4.8 & 45 & 2002.12 .11 & 4.5 & 69 & 2003.02 .12 & 3.6 & 93 & 2003.03 .26 & 4.1 \\
\hline 22 & 2002.10 .20 & 4.1 & 46 & 2002.12 .18 & 4.6 & 70 & 2003.02 .12 & 4.5 & 94 & 2003.03 .27 & 4.7 \\
\hline 23 & 2002.10 .21 & 5.2 & 47 & 2002.12 .20 & 4.1 & 71 & 2003.02 .12 & 4.7 & & & \\
\hline
\end{tabular}

stages, fuzzily divided, differ in characteristic duration (lead time) of alarms: long-term (tens of years); intermediate-term (years); short-term (months), and immediate (days and less). To the best knowledge of the authors most if not all prediction methods, validated one way or another, concern the first 2.5). three stages; the very possibility of short-term and immediate predictions is often doubted (Geller, 1997), while their paramount importance is well recognized. Here, we describe underlying concept of $R T P(2.1)$ and its major elements (2.2- 


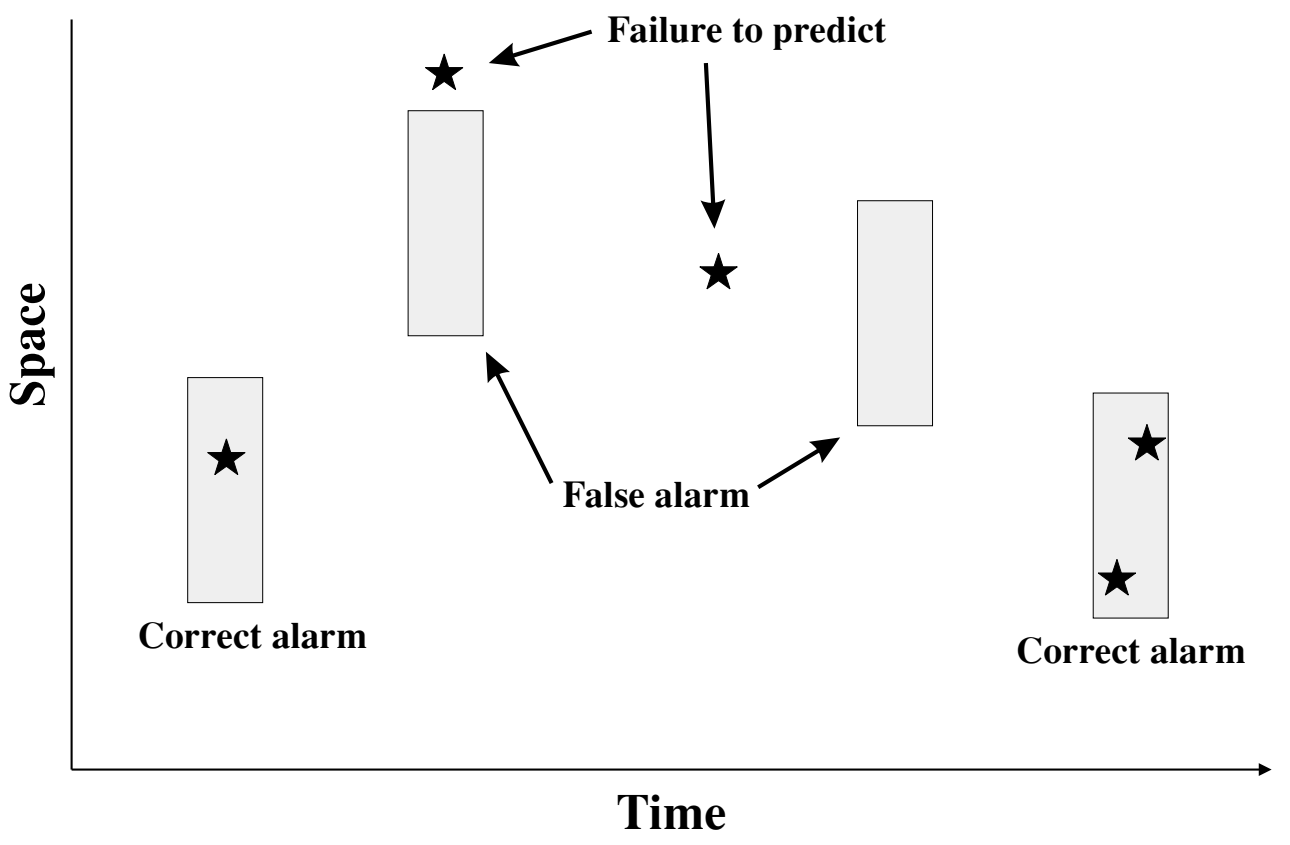

Fig. 2. Possible outcomes of prediction (Keilis-Borok et al., 2004). Stars mark strong earthquakes, targeted by prediction. A box represents the time-space covered by an alarm. A prediction is correct if a strong earthquake occurs within an alarm. Otherwise, this is a false alarm. Failure to predict is the case when a strong earthquake occurs outside of an alarm. Probabilistic component of prediction is represented by the score of errors (Molchan, 2003).

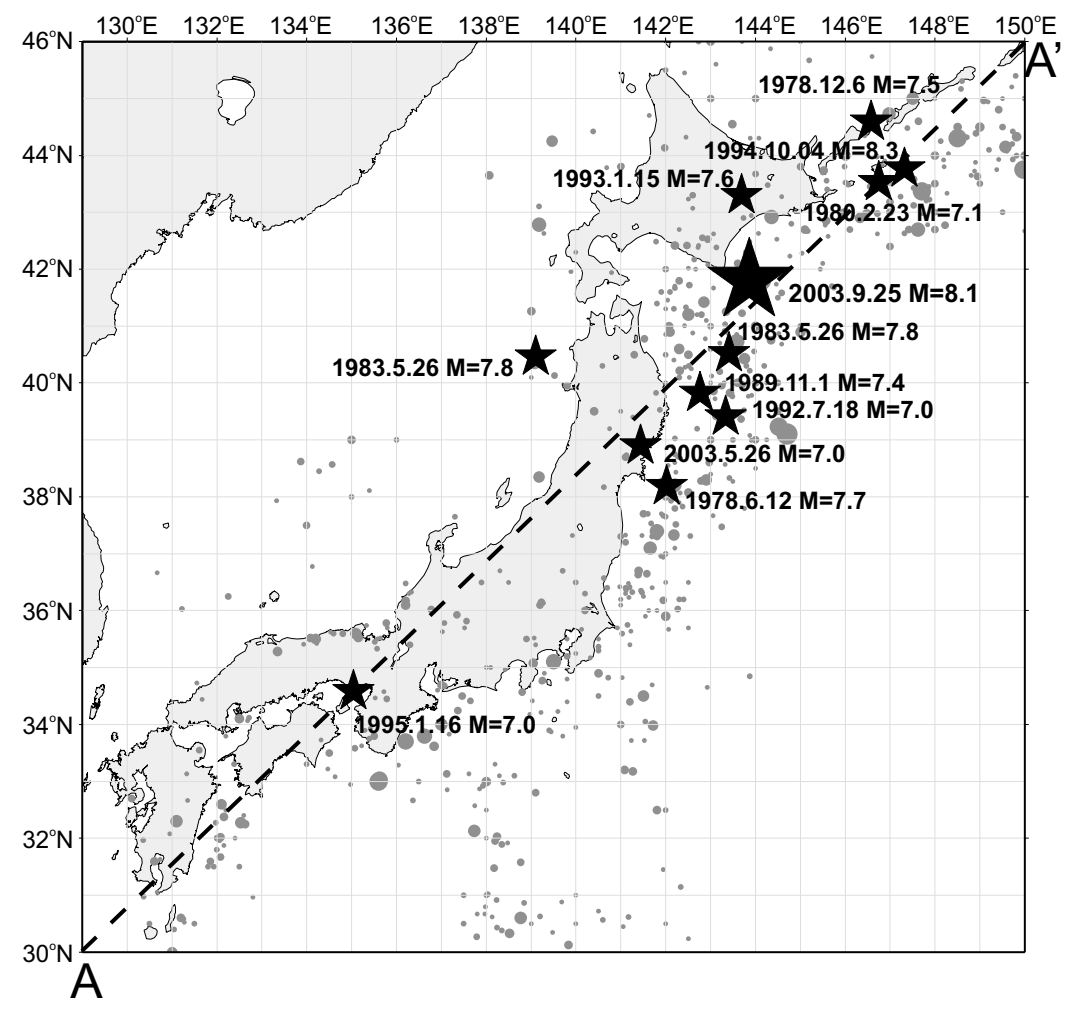

Fig. 3. Japan: territory considered. Stars mark strong earthquakes, targeted for retrospective prediction. Dots show background seismicity for the time considered: epicenters of earthquakes with magnitude $M \geq 5$ with aftershocks eliminated. Large star is the epicenter of Tokachi-oki earthquake, which was predicted by precursory chain, shown in Fig. 1. Dashed line is used in time-distance projection shown in Fig. 4 below.

\subsection{Underlying concept}

The process leading to strong earthquakes is not localized near incipient earthquake source but, being a component of geodynamics, extends over large time and space and evolves in multiple scales (Aki, 2003; Bird, 1998; Blanter and Schnirman, 1997; Bowman et al., 1998; Gabrielov et al., 2000a; Jin et al., 2003; Keilis-Borok, 1996, 2002; KeilisBorok and Soloviev, 2003; Newman et al., 1994; Rundle et 
Table 2. Functions $F_{P}$ capturing different premonitory phenomena.

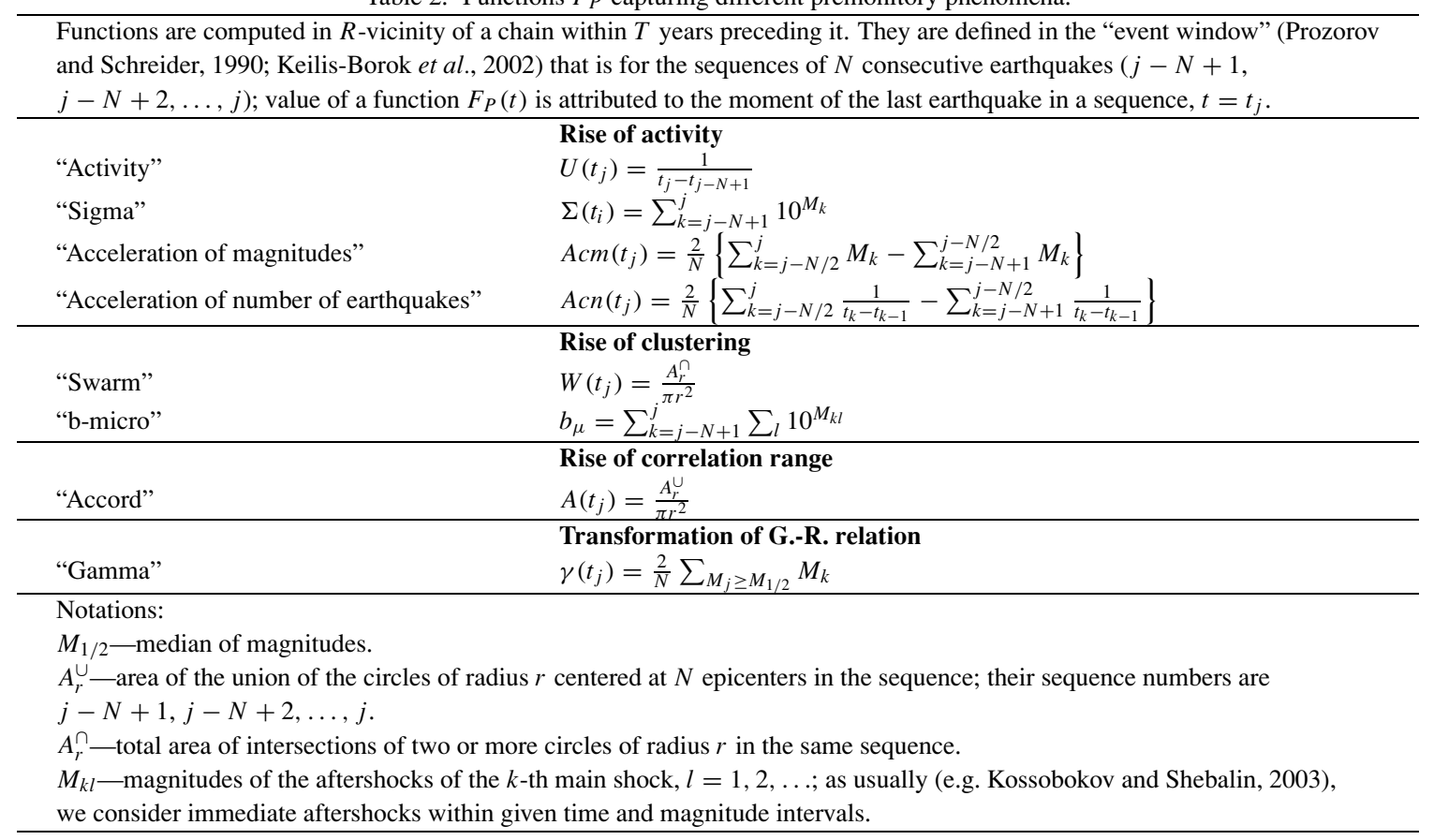

Table 3. Prediction procedure.

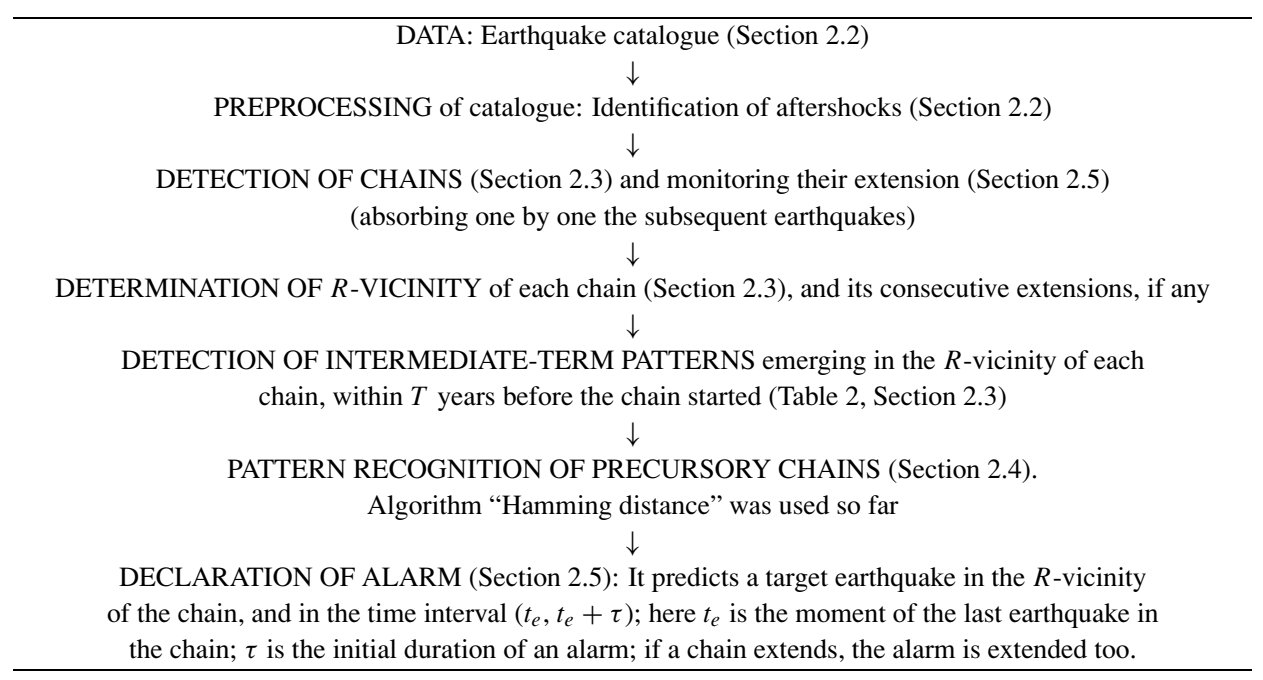

Table 4. Parameters of the chains.

\begin{tabular}{cccccrc}
\hline Region & $M_{\min }$ & $r_{0}, \mathrm{~km}$ & $c$ & $\tau_{0}$, days & $k_{0}$ & $l_{0}, \mathrm{~km}$ \\
\hline Central California & 2.9 & 50 & 0.35 & 30 & 6 & 200 \\
Southern California & 2.9 & 50 & 0.35 & 20 & 6 & 200 \\
Japan & 3.6 & 50 & 0.35 & 20 & 10 & 350 \\
Eastern Mediterranean & 3.0 & 50 & 0.35 & 40 & 6 & 200 \\
\hline
\end{tabular}

al., 2000; Scholz, 1990; Sornette, 2000; Turcotte, 1997; Zaliapin et al., 2003).

RTP captures interaction of geodynamics on the intermediate- and short-term scales. Among earthquake precursors reflecting this process are multi-scale premonitory seismicity patterns - the spatio-temporal patterns of seismicity that emerge as a strong earthquake approaches (Caputo et al., 1983; Gabrielov et al., 2000b; Keilis-Borok, 1996; 2002; Knopoff et al., 1996; Kossobokov and Shebalin, 2003;
Ma et al., 1990; Mogi, 1985; Prozorov and Schreider, 1990; Turcotte, 1997; Shaw et al., 1992; Zaliapin et al., 2002, 2003; Sykes and Jaume, 1990; Kanamori, 2003). Patterns used in $R T P$ reflect two conditions necessary and sufficient to generate a target earthquake: accumulation of energy, to be released by that earthquake; and accumulation of instability, necessary to release this energy triggering that earthquake. Energy is carried by the stress field, instability-by \{strength-stress $\}$ field. 
Japan, 1975-2003, 11+1 earthquakes $M>=7.0$

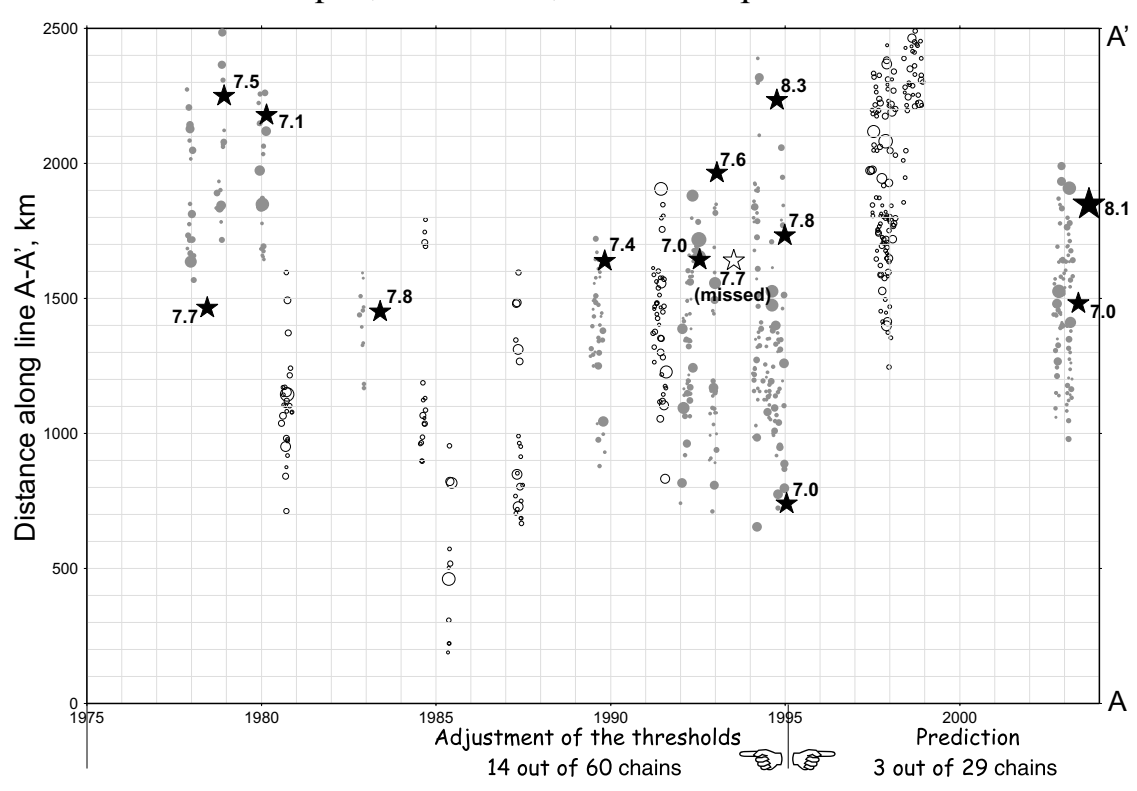

Fig. 4. Japan: chains and strong earthquakes on the time-distance plain. Distance is counted along the dashed line shown on the map in Fig. 3. Filled circles show precursory chains, open circles show the false alarms. Other notations are the same as in Fig. 1.

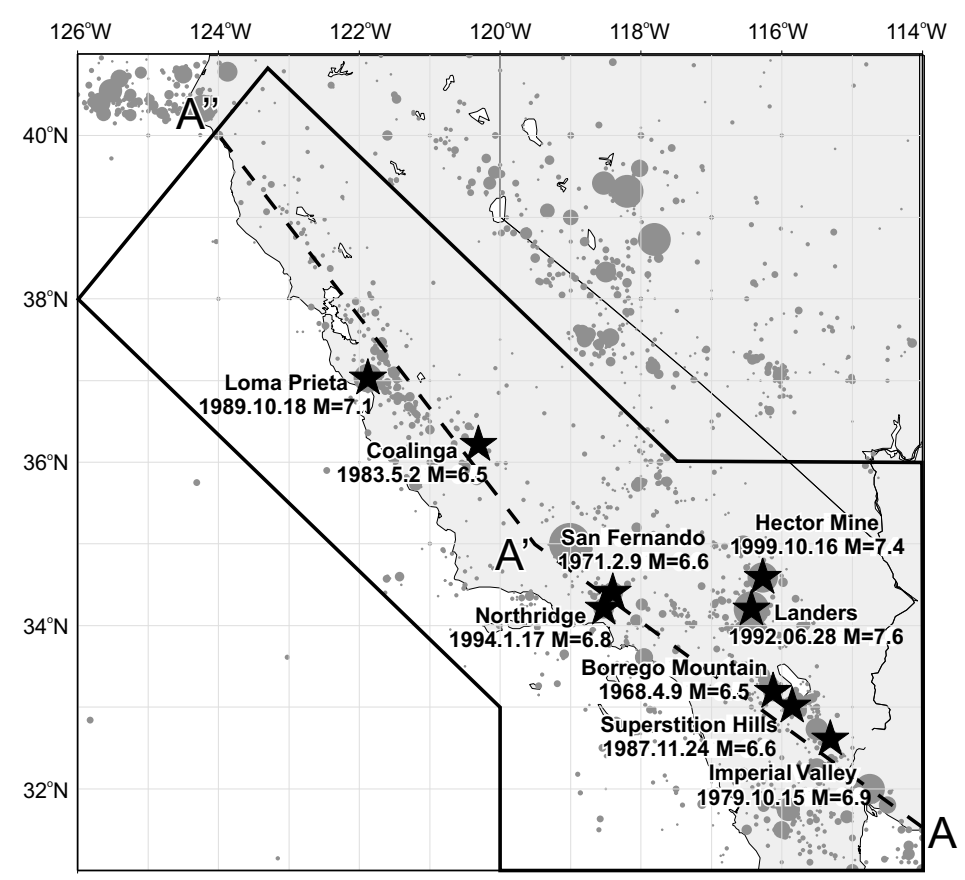

Fig. 5. Southern and Central California: territory considered. Dots show background seismicity: epicenters of earthquakes with magnitude $M \geq 3$ with aftershocks eliminated. Other notations are the same as in Fig. 3.

\subsection{Chain-a candidate for a short-term precursor (Keilis-Borok et al., 2004)}

Definition. A chain is defined as a generalization of patterns Roc and Accord capturing premonitory increase of earthquakes correlation range; these patterns have been found in the modeled seismicity (Gabrielov et al., 2000a, b) and then in observations (Shebalin et al., 2000; Keilis-Borok et al., 2002). Let us call two earthquakes "neighbors" if: (i) the distance between their epicenters does not exceed a threshold $r$; and (ii) the time interval between them does not exceed a threshold $\tau_{0}$. A chain is the sequence of earthquakes connected by the following rule: each earthquake has at least one neighbor in that sequence and no neighbors outside the sequence.

To connect in a chain only the unusually close earthquakes we normalize the threshold $r$ as follows: $r=r_{0} 10^{c(\underline{m}-2.5)}$, where $\underline{m}$ is the magnitude of the smaller earthquake in a pair considered.

Let $k$ be the number of earthquakes in a chain, and $l-$ the maximal distance between their epicenters. To ensure that our chains reflect a considerable rise of the earthquake correlation range, we consider only the chains with $k$ and $l$ 

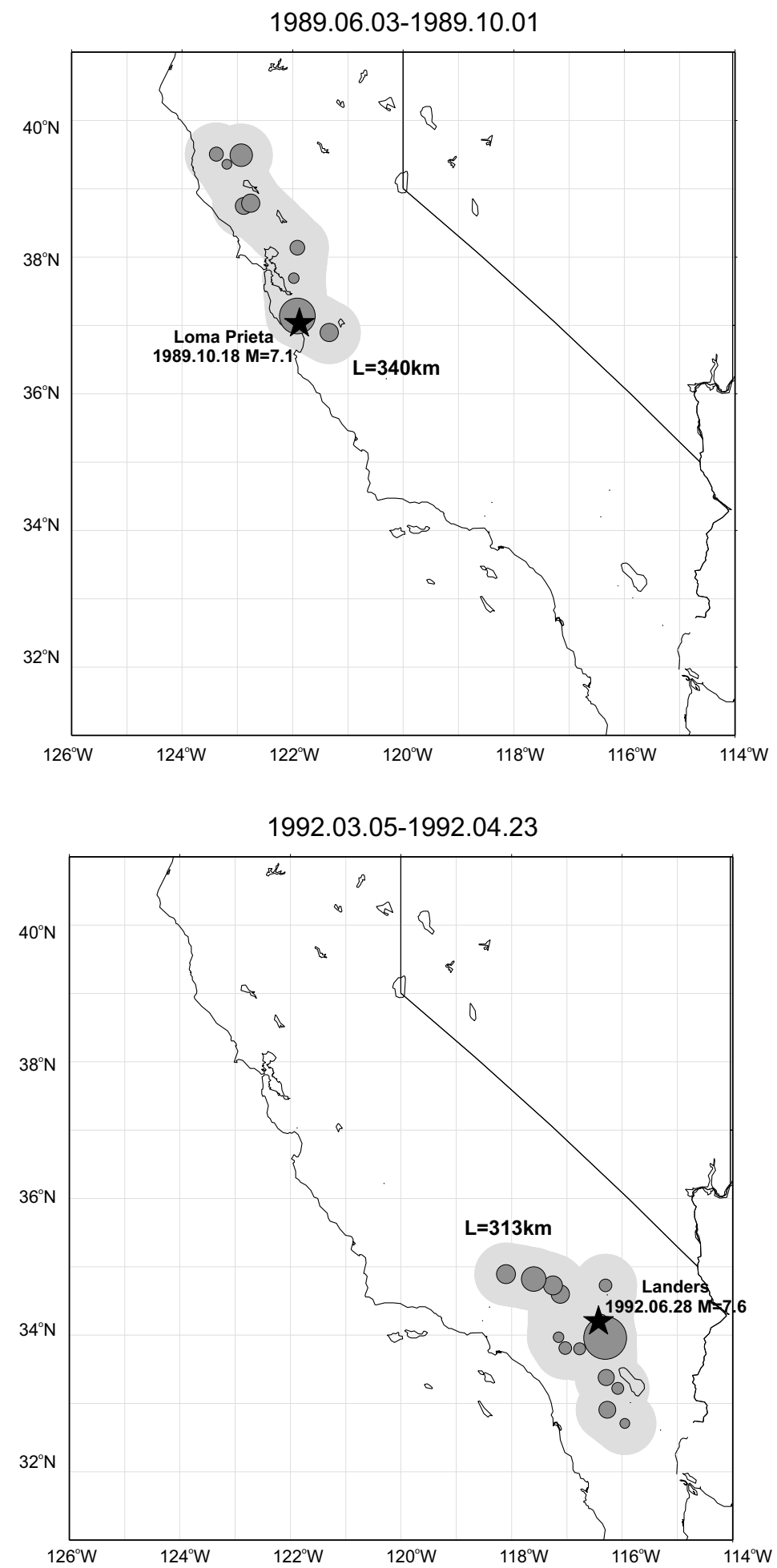

Fig. 6. Southern and Central California: examples of precursory chains. Notations are the same as in Fig. 1.

sufficiently large, $k \geq k_{0}$ and $l \geq l_{0}$.

The need for RTP. Data analysis demonstrates that the chains thus defined do precede most of the target earthquakes with a lead time of months; however up to $80 \%-90 \%$ of the chains would give false alarms if used as short-term precursors. With $R T P$ approach we drastically reduce this rate by considering the chains in conjunction with intermediate-term precursors.

Data source-the earthquake catalogs. Precursors consid- ered are premonitory seismicity patterns determined by analysis of an earthquake catalog with aftershocks eliminated; however the number of immediate aftershocks is retained for each main shock (Keilis-Borok, 2002) Accordingly, earthquake catalog is represented as $\left\{t_{j} ; \varphi_{j}, \lambda_{j}, h_{j} ; m_{j} ; b_{j}\right\}, j=$ $1,2, \ldots$. Here $t_{j}$ is the time of an earthquake, $t_{j}>=t_{j-1}$; $\varphi_{j}$ and $\lambda_{j}$-latitude and longitude of its epicenter; $h_{j}$-focal depth; and $m_{j}$-its magnitude. We consider the earthquakes with magnitude $M \geq M_{\min }$. Focal depth is not used in this 


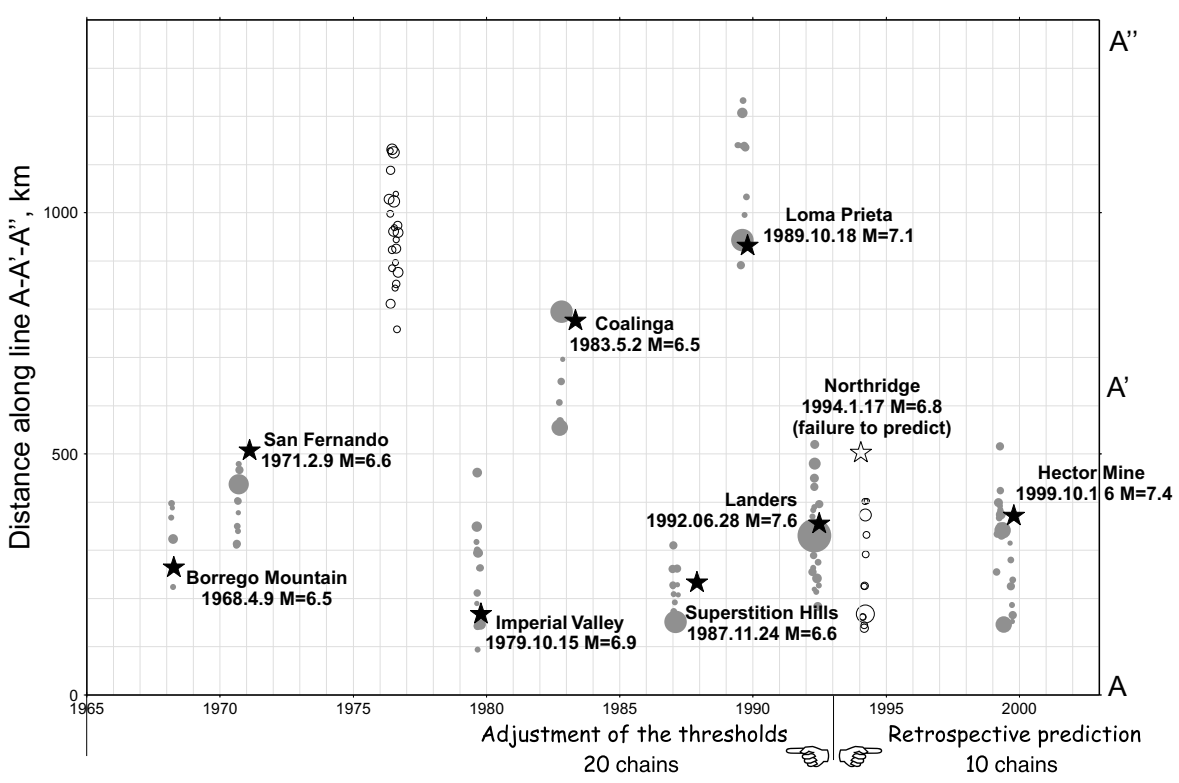

Fig. 7. Southern and Central California: chains and strong earthquakes on the time-distance plain. Notations are the same as in Fig. 4.

study, except that we consider the earthquakes with $h_{j} \leq 100$ $\mathrm{km}$. Aftershocks have been identified by the windowing described in Keilis-Borok et al. (2002) and Knopoff et al. (1996).

\subsection{Intermediate-term patterns discriminating precur- sory and non-precursory chains}

The problem. We hypothesize that a precursory chain (as opposed to a false alarm) is preceded by intermediate-term precursors formed in its vicinity. If that hypothesis is correct, reverse order of analysis has an important advantage: it indicates the areas and time intervals where one should look for the intermediate-term precursors. To test that hypothesis we have to define formally these precursors and the vicinity of the chain.

$R$-vicinity of a chain. It is defined as the union of circles of radius $R$ centered at the epicenters of the chain; its border is a smoothed envelope of these circles (Keilis-Borok et al., 2004). In the $R$-vicinity of each chain we will look for intermediate-term patterns within $T$ years preceding the chain, that is in the time-interval $\left(t_{0}-T, t_{0}\right)$; here $t_{0}$ is the time of the first earthquake in the chain.

Intermediate-term patterns (Keilis-Borok, 1990; KeilisBorok and Shebalin, 1999; Kossobokov and Shebalin, 2003; Keilis-Borok et al., 2004). We consider here eight patterns; four of them capture premonitory rise of seismic activity, two-rise of clustering, one-rise of correlation range (more specifically-spreading of seismicity over the fault network) and one-transformation of magnitude-frequency (Gutenberg-Richter's) relation. Let us briefly remind their formal definition (Keilis-Borok, 1990, 1996, 2002; KeilisBorok and Shebalin, 1999; Gabrielov et al., 2000b; Kossobokov and Shebalin, 2003; Zaliapin et al., 2002, 2003). To detect a pattern $P$ we compute a function $F_{P}(t)$ defined on the earthquake sequence. Emergence of a pattern at the moment $t$ is captured by condition $F_{P}(t) \geq C_{P}$, where $C_{P}$ is an adjustable threshold. Functions considered here are given in Table 2.

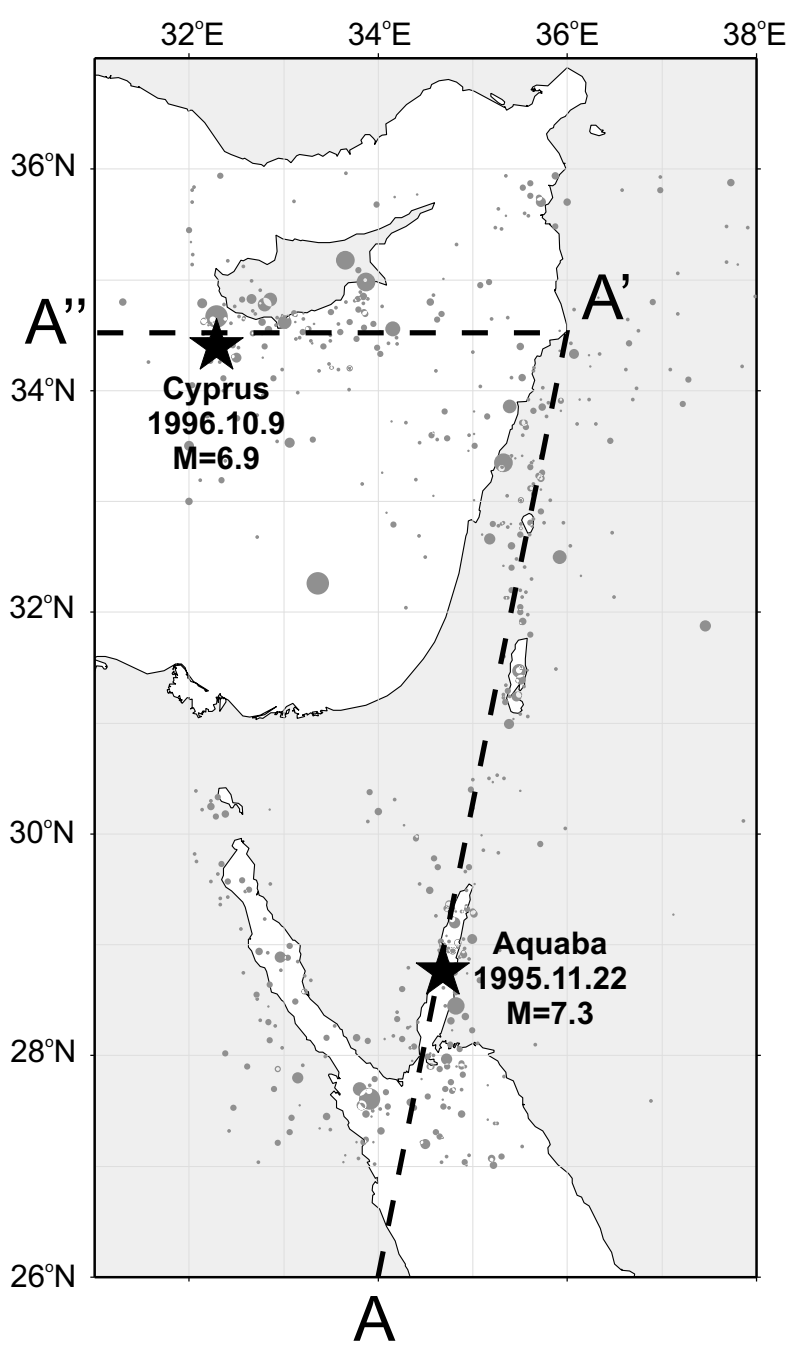

Fig. 8. Eastern Mediterranean: territory considered. Dots show background seismicity: epicenters of earthquakes with magnitude $M \geq 3$ with aftershocks eliminated. Other notations are the same as in Fig. 3 . 


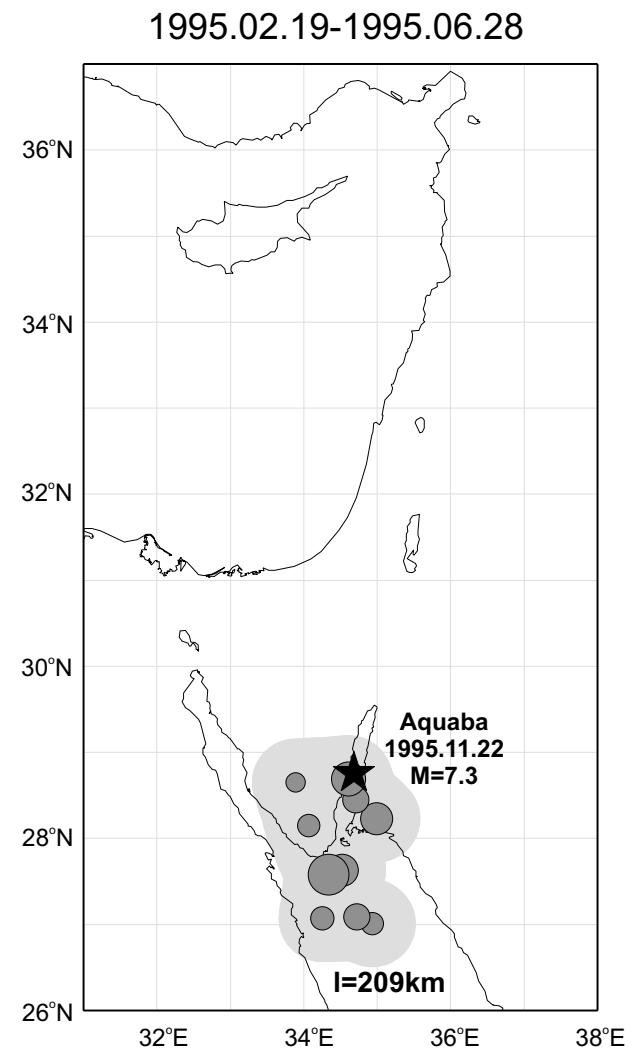

1996.03.10-1996.06.19

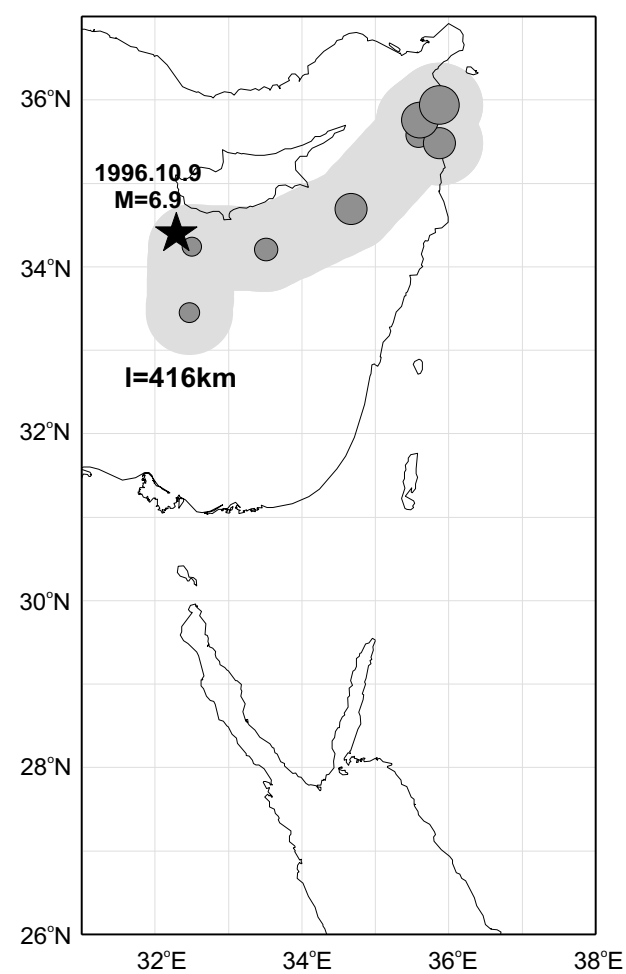

Fig. 9. Eastern Mediterranean: examples of precursory chains. Notations are the same as in Fig. 1.

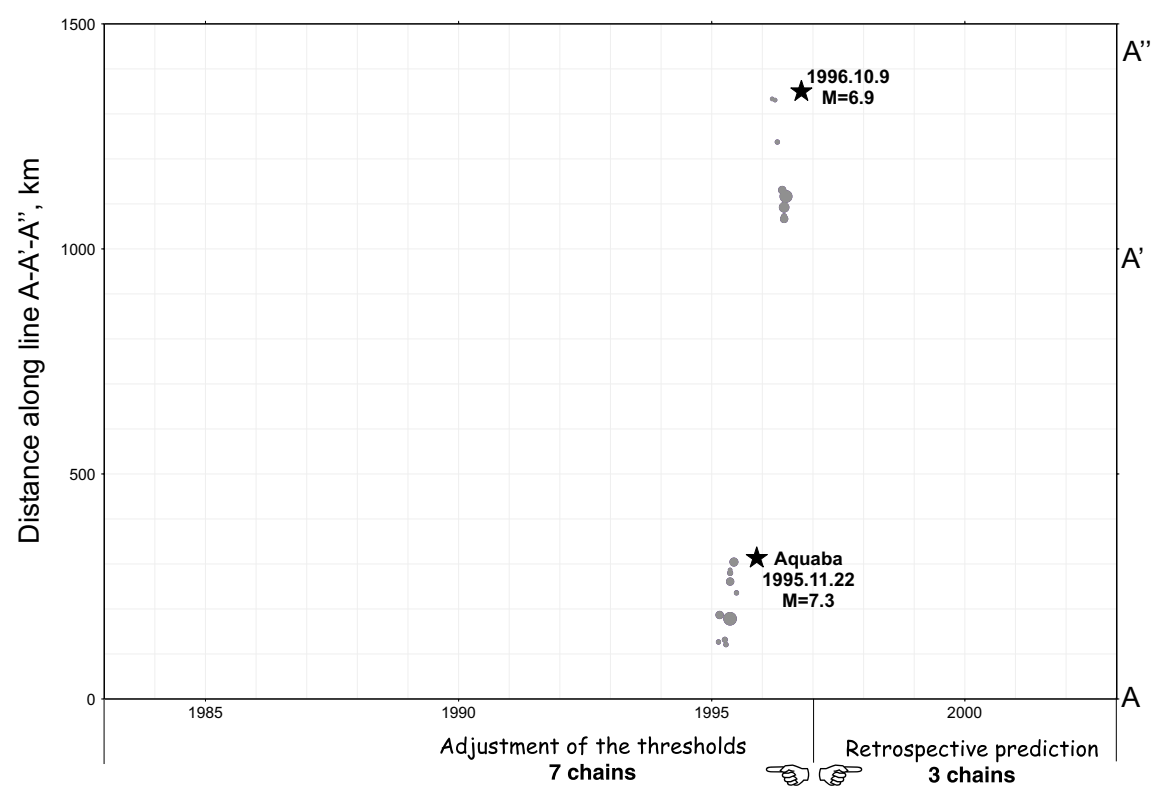

Fig. 10. Eastern Mediterranean: chains and strong earthquakes on the time-distance plain. Notations are the same as in Fig. 4.

Adjustment of parameters. We had to adjust for each region the values of numerical parameters in definition of the chains and intermediate-term patterns, and the values of thresholds $C_{P}$. Each threshold $C_{P}$ is determined automatically; it minimises the total rate of the errors of each kindfailures to predict and false alarms - in prediction with a single pattern $P$. As always, the retrospective results should be tested on independent data, not used in obtaining these results (Gelfand et al., 1976; Keilis-Borok and Soloviev,
2003). To save the data for such tests, we used for adjustment only the first two thirds of the chains in each region. The remaining chains have been used to estimate the rate of the errors.

\subsection{Recognition of precursory chains}

We have now a classical pattern recognition problem: to find a combination of patterns that discriminate precursory and non-precursory chains. We used the relatively simple pattern recognition algorithm "Hamming distance" that has 
a good track record in geophysics (e.g. Vorobieva, 1999). Its application gives the following recognition rule. Each of the eight patterns listed in Section 2.3 was computed with eight sets of numerical parameters, so that altogether 64 patterns are considered. A chain is recognized as precursory if it is preceded by $C$ or more different patterns out of 64 considered. Threshold $C$ controls the tradeoff between the rates of false alarms and failures to predict (Molchan, 2003).

\subsection{Alarms}

Emergence of precursory chain triggers an alarm in its $R$ vicinity for the $\tau$ months; statistics of past alarms, mainly retrospective so far, suggests $\tau=$ nine months. An alarm is not called off after a target earthquake occurred, since a second target earthquake might occur in the same timearea. After a chain reached the thresholds $k \geq k_{0}, l \geq l_{0}$ it may keep growing. Then RTP analysis is repeated when chain accumulates each new earthquake. After each such extension the identification of chain may remain the same or reverse. New alarms will be announced accordingly, while the previous alarms are not called off.

Possible outcomes of such predictions are illustrated in Fig. 2. Probabilistic component of predictions is expressed in the probabilities of errors (Molchan, 2003). Similar formulation is used in many intermediate-term prediction algorithms (Kossobokov and Shebalin, 2003; Keilis-Borok (ed.), 1990; Keilis-Borok and Shebalin (eds.), 1999). Performance of prediction algorithm is characterized by the rate of false alarms $f$, rate of failures to predict $n$, and time-area $\tau$ occupied by all alarms in $\%$ to the total time-area considered (Molchan, 2003). We measured the areas by the number of main shocks with $M \geq 4.0$ (Kossobokov and Shebalin, 2003). Sequence of operations realising $R T P$ data analysis is summed up in Table 3.

\section{Data Analysis}

We applied RTP approach to Japan (1975-2003), southern and central California (1965-2003), and Eastern Mediterranean (1980-2003). In total 23 target earthquakes were considered. Values of numerical parameters are given in Tables 4,5 .

\subsection{Japan, January 1975-March 2003}

Territory considered is shown in Fig. 3, along with epicenters of 12 target earthquakes, $M \geq 7$. We analyzed the catalog of Japanese Meteorological Agency (JMA). Numerical parameters have been adjusted on the data for 19751994, and used in the test for 1995-2003. Two of the target earthquakes occurred within the test period: May 26, 2003, $M=7$, and Sept. 25, 2003, $M=8.1$; the last one is Tokachioki earthquake (Section 1).

We have found 60 chains in the period of adjustment and 29 chains in the test period. Respectively 14 and 3 chains have been selected as precursory; they are juxtaposed with target earthquakes in Fig. 4. Within test period two precursory chains gave false alarms. Alarms occupy $7.4 \%$ of the total time-area considered.

The last chain, ended on March 27, 2003 (see the last date in Table 1) gave a correct alarm; it preceded two target earthquakes by two and six months respectively.
Table 5. Parameters of intermediate-term patterns.

\begin{tabular}{crllcc}
\hline Variant & $R, \mathrm{~km}$ & $n^{*}$ & $N$ & $r, \mathrm{~km}$ & $T$, years \\
\hline 1 & 100 & 20 & 50 & 50 & 2 \\
2 & 50 & 10 & 50 & 50 & 2 \\
3 & 100 & 20 & 20 & 50 & 2 \\
4 & 50 & 10 & 20 & 50 & 2 \\
5 & 100 & 20 & 50 & 50 & 0.5 \\
6 & 50 & 10 & 50 & 50 & 0.5 \\
7 & 100 & 20 & 20 & 50 & 0.5 \\
8 & 50 & 10 & 20 & 50 & 0.5 \\
\hline
\end{tabular}

\subsection{Southern and Central California, January 1965- June 2003}

Territory considered is shown in Fig. 5, along with epicenters of 9 target earthquakes, $M \geq 6.4$. We analyzed the catalogs of Advanced National Seismic System (ANSS). Numerical parameters have been adjusted on the data for 19651998, and used in the test for 1999-2003. Two of the target earthquakes occurred within the test period:

We have found 20 chains in the period of adjustment and 10 chains in the test period. Examples of the chains are given in Fig. 6. Respectively 8 and 2 chains have been selected as precursory; Figure 7 juxtaposes them with target earthquakes. Within the test period one precursory chain gave a false alarm, one gave correct prediction, and one target earthquake (Northridge, 1994) was missed by prediction. Alarms occupy $7.4 \%$ of the time-area considered.

\subsection{Eastern Mediterranean, January 1980-June 2003}

Territory considered is shown in Fig. 8, along with epicenters of 2 target earthquakes, $M>6.5$. We analyzed the catalog of Geophysical Institute of Israel (GII). Numerical parameters have been adjusted on the data for 1980-1997, and used in the test for 1998-2003. Both target earthquakes occurred in the adjustment period.

We have found 7 chains in the adjustment period and 3 chains in the test period. Examples of the chains are given in Fig. 9. Retrospectively only 2 chains have been selected as precursory (Fig. 9), both in adjustment period; Figure 10 juxtaposes them with target earthquakes on time-distance plain. Comparing to other regions we see less target earthquakes, less chains, and (possibly due to that)—no errors. In the test period no target earthquakes occurred and no chains have been detected. Alarms occupy $2.9 \%$ of the time-space considered.

We hope that this overview of RTP method gives an idea how the precursor to Tokachi-oki earthquake has been detected. Detailed description of that method is far beyond the scope of this paper and will be published elsewhere.

Altogether the described results well justify continuation of experiments in advance prediction. In further development of RTP analysis two problems seem to deserve particular attention: using other relevant fields (Press, 1965; Uyeda and Park, 2002); and development of prediction algorithm with complete self-adaptation to a region considered.

Acknowledgments. This study was made possible by the 21 st Century Collaborative Activity Award for Studying Complex Sys- 
tems, granted by the James S. McDonnell Foundation (project "Understanding and Prediction of Critical Transitions in Complex Systems") and by ISTC project 1538. The staple of our work are the earthquake catalogs, laboriously, timely and competently compiled by Japanese Meteorological Agency (JMA), Advanced National Seismic System (ANSS), Southern California Earthquake Data Center (SCEDC), Geophysical Institute of Israel (GII). JMA catalog was received through the Japan Meteorological Business Support Center. We are grateful for tough constructive criticism to K. Aki, M. Ghil, A. Jin, A. Soloviev, D. Turcotte and to D. Shatto for patient help in preparation of the manuscript. Extremely useful were discussions at Hagiwara Symposium and at the Seventh Workshop on Non-Linear Dynamics and Earthquake Prediction in the Abdus Salam International Centre for Theoretical Physics, Trieste.

\section{References}

Aki, K., Introduction to seismology for earthquake prediction, Proceedings of the Seventh Workshop on Non-Linear Dynamics and Earthquake Prediction, International Center for Theoretical Physics, Trieste, preprint, 2003.

ANSS/CNSS Worldwide Earthquake Catalog, produced by Advanced National Seismic System (ANSS) and hosted by the Northern California Data Center (NCEDC), 1965-2003, http://quake.geo.berkeley.edu/anss.

Bird, P., Testing hypotheses on plate-driving mechanisms with global lithosphere models including topography, thermal structure, and faults, $J$. Geophys. Res., 103(B5), 10115-10129, 1998.

Blanter, E. M. and M. G. Shnirman, Simple hierarchical systems: stability, self-organized criticality and catastrophic behavior, Phys. Rev. E, 55(6), 6397-6403, 1997.

Bowman, D. D., G. Ouillon, C. G. Sammis, A. Sornette, and D. Sornette, An observational test of the critical earthquake concept, J. Geophys. Res., 103, 24359-24372, 1998.

Caputo, M., R. Console, A. M. Gabrielov, V. I. Keilis-Borok, and T. V. Sidorenko, Long-term premonitory seismicity patterns in Italy, Geophys. J. R. Astron. Soc., 75, 71-75, 1983.

Gabrielov, A., V. Keilis-Borok, I. Zaliapin, and W. I. Newman, Critical transitions in colliding cascades, Phys. Rev. E, 62(1), 237-249, 2000a.

Gabrielov, A. M., I. V. Zaliapin, W. I. Newman, and V. I. Keilis-Borok, Colliding cascades model for earthquake prediction, Geophys. J. Int., 143, 427-437, 2000b.

Gelfand, I. M., Sh. A. Guberman, V. I. Keilis-Borok, L. Knopoff, F. Press, E. Ya. Ranzman, I. M. Rotwain, and A. M. Sadovsky, Pattern recognition applied to earthquake epicenters in California, Phys. Earth Planet. Inter., 11, 227-283, 1976.

Geller, R. J., Earthquake prediction: A critical review, Geophys. J. Int., 131, 425-450, 1997.

Jin, A., K. Aki, Z. Liu, and V. I. Keilis-Borok, Brittle-ductile interaction hypothesis for earthquake loading, Abstract, Hagiwara Symposium, XXIII General Assembly of IUGG, 2003, Sapporo, Japan, 2003.

Kanamori, H., Earthquake prediction: An overview, in International Handbook of Earthquake \& Engineering Seismology, Volume 81B, edited by W. H. K. Lee, H. Kanamori, P. C. Jennings, and C. Kisslinger, pp. 12051216, Academic Press, London, 2003.

Keilis-Borok, V. I. (ed.), Intermediate-term earthquake prediction: Models, algorithms, worldwide tests, Phys. Earth Planet. Inter., 61, special issue, 1990

Keilis-Borok, V. I., Intermediate-term earthquake prediction, Proc. Nat. Acad. Sci., 93, 3748-3755, 1996.

Keilis-Borok, V., Earthquake prediction: state-of-the-art and emerging possibilities, invited to Annu. Rev. Earth Planet. Sci., 30, 2002.

Keilis-Borok, V., Fundamentals of earthquake prediction: Four paradigms, in Nonlinear Dynamics of the Lithosphere and Earthquake Prediction, edited by V. I. Keilis-Borok and A. A. Soloviev, pp. 1-36, SpringerVerlag, Heidelberg, 2003.

Keilis-Borok, V. I. and I. M. Rotwain, Diagnosis of time of increased probability of strong earthquakes in different regions of the world: algorithm CN, Phys. Earth Planet. Inter., 61(1-2), 57-72, 1990.

Keilis-Borok, V. I. and P. N. Shebalin (eds.), Dynamics of the lithosphere and earthquake prediction, Phys. Earth Planet. Inter., special issue, 111, 179-330, 1999.
Keilis-Borok, V. I. and A. A. Soloviev (eds.), Nonlinear Dynamics of the Lithosphere and Earthquake Prediction, 335 pp., Springer-Verlag, Heidelberg, 2003.

Keilis-Borok, V. I., P. N. Shebalin, and I. V. Zaliapin, Premonitory patterns of seismicity months before a large earthquake: Five case histories in Southern California, Proc. Natl. Ac. Sci., 99(26), 16562-16567, 2002.

Keilis-Borok, V., P. Shebalin, A. Gabrielov, and D. Turcotte, Reverse tracing of short-term earthquake precursors, Phys. Earth Planet. Inter., 145, 1-4, 75-85, 2004.

Knopoff, L., T. Levshina, V. I. Keilis-Borok, and C. Mattoni, Increased long-range intermediate-magnitude earthquake activity prior to strong earthquakes in California, J. Geophys. Res., 101, 5779-5796, 1996.

Kossobokov, V. G. and J. M. Carlson, Active zone size vs. activity: A study of different seismicity patterns in the context of the prediction algorithm M8, J. Geophys. Res., 100, 6431-6441, 1995.

Kossobokov, V. and P. Shebalin, Earthquake prediction, in Nonlinear Dynamics of the Lithosphere and Earthquake Prediction, edited by V. I. Keilis-Borok and A. A. Soloviev, pp. 141-207, Springer-Verlag, Heidelberg, 2003.

Ma, Z., Z. Fu, Y. Zhang, C. Wang, G. Zhang, and D. Liu, Earthquake Prediction: Nine Major Earthquakes in China, Springer, New York, 1990.

Mogi, K., Earthquake Prediction, Academic Press, Tokyo, 1985.

Molchan, G. M., Earthquake prediction strategies: A theoretical analysis, in Nonlinear Dynamics of the Lithosphere and Earthquake Prediction, edited by V. I. Keilis-Borok and A. A. Soloviev, pp. 209-237, SpringerVerlag, Heidelberg, 2003.

Newman, W. I., A. Gabrielov, and D. L. Turcotte (eds.), Nonlinear Dynamics and Predictability of Geophysical Phenomena, Geophys. Monographs Ser. 83. Am. Geophys. Union, Washington, DC, 83, 1994.

Press, F. (ed.), Earthquake Prediction: A Proposal for a Ten Year Program of Research, 134 pp., Ad Hoc Panel on Earthquake Prediction, White House Office of Science and Technology, Washington, DC, 1965.

Prozorov, A. G. and S. Yu. Schreider, Real time test of the long-range aftershock algorithm as a tool for mid-term earthquake prediction in Southern California, Pure Appl. Geophys., 133, 329-347, 1990.

Rundle, J., D. Turcotte, and W. Klein (eds.), Geocomplexity and the Physics of Earthquakes, American Geophysical Union, Washington, DC, 2000.

Scholz, C. H., The Mechanics of Earthquakes and Faulting, Cambridge University Press, Cambridge, 1990.

Shaw, B. E., J. M. Carlson, and J. S. Langer, Patterns of seismic activity preceding large earthquakes, J. Geophys. Res., 97, 479, 1992.

Shebalin, P., I. Zaliapin, and V. I. Keilis-Borok, Premonitory rise of the earthquakes' correlation range: Lesser Antilles, Phys. Earth Planet. Int., 122(3-4), 241-249, 2000

Shebalin, P., V. I. Keilis-Borok, I. Zaliapin, S. Uyeda, T. Nagao, and N. Tsybin, Short-term Premonitory Rise of the Earthquake Correlation Range, Abstract, Hagiwara Symposium, XXIII General Assembly of IUGG, 2003, Sapporo, Japan, 2003.

Sornette, D., Critical Phenomena in Natural Sciences: Chaos, Fractals, Self-organization and Disorder: Concepts \& Tools, Springer Ser. Synerg., 432 pp., Springer-Verlag, Heidelberg, 2000.

Sykes, L. R. and S. C. Jaume, Seismic activity on neighbouring faults as a long-term precursor to large earthquakes in the San Francisco Bay area, Nature, 348, 595-599, 1990.

Turcotte, D. L., Fractals and Chaos in Geology and Geophysics, 2nd ed., 412 pp., Cambridge University Press, Cambridge, 1997.

Uyeda, S. and S. Park (eds.), special issue, Proceedings of the International Symposium on The Recent Aspects of Electromagnetic Variations Related with Earthquakes, 20 and 21 December 1999, J. of Geodynamics, 33, 4-5, 2002.

Vorobieva, I. A., Prediction of a subsequent strong earthquake, Phys. Earth Planet. Inter, 111, 197-206, 1999.

Zaliapin, I., V. I. Keilis-Borok, and G. Axen, Premonitory spreading of seismicity over the faults' network in southern California: Precursor Accord, J. Geophys. Res., 107(B10), 2221, 2002.

Zaliapin, I., V. I. Keilis-Borok, and M. Ghil, A Boolean delay equation model of colliding cascades, Part II: Prediction of critical transitions, $J$. Stat. Phys., 111, 3-4, 839-861, 2003.

P. Shebalin (e-mail: shebalin@mitp.ru), V. Keilis-Borok (e-mail: vkb@ess.ucla.edu), I. Zaliapin, S. Uyeda, T. Nagao, and N. Tsybin 